\section{References}

1. Schrier SA, Bodurtha JN, Burton B, Chudley AE, Chiong MAD, D'avanzo MG, et al. The Coffin-Siris syndrome: a proposed diagnostic approach and assessment of 15 overlapping cases. Am J Med Genet A. 2012;158A:1865-76.
2. Levy P, Baraitser M. Syndrome of the month: Coffin-Siris syndrome. J Med Genet. 1991;28:338-41.

3. Pallotta R. Ocular anomalies in Coffin-Siris syndrome. Ophthalmic Paediatr Genet. 1985;6:109-12.

\title{
Digital photo-editing in preoperative counselling for cosmetic corneal tattooing
}

\author{
Tariq Ayoub $^{1} \cdot$ Tom Henry Flynn ${ }^{1}$
}

Received: 6 March 2019 / Accepted: 18 March 2019 / Published online: 28 March 2019

(c) The Royal College of Ophthalmologists 2019

Corneal tattooing is a well-described procedure for reconstructive cosmetic purposes [1] and for optical purposes [2]. It can serve as an excellent alternative to the use of cosmetic contact lens. However, it is often difficult to explain to patients the cosmetic outcome of the procedure. We describe the use of digital image editing software to aid preop counselling.

\section{Case}

A 42-year-old man presented with a blind left eye and a scarred and opaque left cornea after childhood trauma. He was bothered by the appearance of the eye (Fig. 1a). He failed a trial of cosmetic contact lens-he found it inconvenient and hard to handle the lens and eventually lost it. He was offered corneal tattooing but was concerned with the post-operative cosmetic outcome of the procedure.

To aid preoperative counselling, we used digital photograph-editing software (Powerpoint, Microsoft, Redmond, WA, USA) to alter a picture of his face and simulate the outcome of corneal tattooing (Fig. 1b). After counselling, he was keen to proceed.

Tom Henry Flynn

tom.flynn@nhs.net

1 Moorfields Eye Hospital, 162 City Road, London EC1V 2PD, UK
The surgery was carried out using black sterile medical ink used in radiotherapy patients (off-label use). A 4-mm "pupil" was marked on the corneal surface with a skin trephine dipped in gentian violet. A 300-micron incision was made circumferentially around this mark for $90^{\circ}$. A lamellar dissection was performed within the limits of the "pupil" mark. The ink was injected and spread within this pocket and the incision was closed with a single interrupted 10-0 nylon suture. The tip of a curved needle from a 10.0 nylon suture was dipped in the ink and used to mark the peripheral cornea with a series of short tangential passes in order to simulate the slightly darker appearance near the limbus of light irides. The patient was prescribed dexamethasone $0.1 \%$ qds and $\mathrm{G}$ Chloramphenicol $0.5 \%$ qds post operatively.

post-operative appearance closely resembled the preoperativesimulation and the patient was pleased (Fig. 1c).

\section{Discussion}

Failure to meet the cosmetic expectation and perceived deficits in informed consent can cause dissatisfaction for patients after facial cosmetic procedures [3]. We report a case of a satisfied patient where the outcome of surgery was very similar to that seen in the simulation created preoperatively on photo-editing software. Use of such software is an easily accessible and effective tool to counsel patients of the outcome of cosmetic corneal tattooing preoperatively. 



Fig. 1 Preoperative photograph (a) showing the opaque left cornea. Photo editing of the photograph simulated the post-operative appearance (b). The actual appearance 6 weeks after surgery (c) was similar to the simulation

\section{Compliance with ethical standards}

Conflict of interest The authors declare that they have no conflict of interest.

Publisher's note: Springer Nature remains neutral with regard to jurisdictional claims in published maps and institutional affiliations.

\section{References}

1. Pitz S, et al. Corneal tattooing: an alternative treatment for disfiguring corneal scars. Br J Ophthalmol. 2003;86:397-9.

2. Khan AO, Meyer D. Corneal tattooing for the treatment of debilitating glare in a child with traumatic iris loss. Am Journal of Ophthalmol. 2005;139:920-1.

3. Kandinov A, et al. Analysis of factors associated with rhytidectomy malpractice litigation cases. JAMA Facial Plast Surg. 2017;19: 255-9.

\title{
How stressful is cataract surgery for consultants and ophthalmic trainees? Phacoemulsification is a stressful experience for young consultants
}

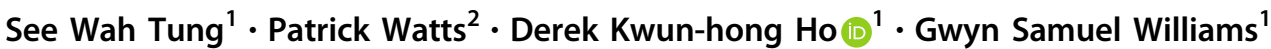

Received: 24 September 2018 / Revised: 5 March 2019 / Accepted: 8 March 2019 / Published online: 1 April 2019

(c) The Royal College of Ophthalmologists 2019

\section{Introduction}

It has long been recognized that intraoperative stress is worse for inexperienced cataract surgeons [1]. Sleep quality is thought to be a big factor in determining stress levels

See Wah Tung

annieswtung@ doctors.org.uk

$\triangle$ Gwyn Samuel Williams gwynwilliams@doctors.org.uk

1 Department of Ophthalmology, Singleton Hospital, Sketty Lane, Swansea SA2 8QA, UK

2 Department of Ophthalmology, University Hospital of Wales, Heath Park Way, Cardiff CF14 4XW, UK during surgical procedures, with poor sleep being a big contributor [2]. Stress is associated with underperformance which can affect the functioning of an entire surgical unit [3]. It is therefore vital to understand the often underreported prevalence of stress amongst trainee and consultant cataract surgeons, and to this end we circulated an online survey to every ophthalmic trainee and consultant ophthalmic surgeon in Wales to determine the levels of stress experienced as a direct result of cataract surgery.

\section{Methods}

The Maslach Burnout Inventory (MBI) is a well respected study for assessing stress and burnout [4]. Section A of this questionnaire deals specifically with stress and consists of 